\title{
UM ESTUDO EXPLORATÓRIO PARA A INSERÇÃO DA ASTRONOMIA NA FORMAÇÃO DE PROFESSORES DOS ANOS INICIAIS DO ENSINO FUNDAMENTAL ${ }^{1}$
}

\section{An EXPLORATORY STUDY FOR INSERTING Astronomy In PRIMARY SCHOOL TEACHER'S EDUCATION}

\author{
Rodolfo Langhi* \\ rlanghi@fc.unesp.br \\ Roberto Nardi*** \\ nardi@fc.unesp.br
}

\section{Resumo}

A pesquisa aqui descrita objetivou identificar padrões relativos às perspectivas dos professores dos anos iniciais do Ensino Fundamental em relação ao ensino da Astronomia, bem como as expectativas dos mesmos sobre uma possível inserção deste tema na formação de docentes. A pesquisa, de natureza qualitativa, foi norteada por uma revisão crítica da literatura e pela aplicação das técnicas de entrevistas semi-estruturadas a uma amostra de cinco professores predominantemente da Escola Pública. As representações dos docentes sobre temas astronômicos e as abordagens de suas inquietações em relação ao ensino da Astronomia foram interpretadas ao final da investigação mediante a análise de seus discursos. A análise dos dados obtidos neste estudo fornece subsídios para a implementação de um programa de educação continuada, visando uma mudança de postura na prática pedagógica dos docentes.

Palavras-chave: Ensino de Astronomia, formação de professores dos anos iniciais do Ensino Fundamental, concepções alternativas em Astronomia, erros conceituais em livros didáticos, análise do discurso.

1 Este artículo fue elaborado con base en la ponencia presentada por los autores en el IX Encontro de Pesquisa em Ensino de Fisica realizado en Brasil (septiembre/2003).

* Grupo de Pesquisa em Ensino de Ciências, Mestrando em Educação para a Ciência. Faculdade de Ciências, UNESP Câmpus de Bauru, São Paulo, Brasil.

** Grupo de Pesquisa em Ensino de Ciências, Professor Assistente Doutor, Depto. de Educação, Faculdade de Ciências, UNESP, Câmpus de Bauru, São Paulo, Brasil. 


\section{Abstract}

The research identifies some patterns related to initial years of Primary School teachers' perspectives in relation to the teaching of the Astronomy as well as their perpsectivers about a possible insert of this theme in the initial and continuous formation of teachers. The study, of qualitative nature, is orientated by a critical revision of the literature in the area and the analysis of the discourses of a teachers' sample of the initial years of the Primary School. The teachers' enunciations about astronomical themes and their inquietudes in relation to the teaching of the Astronomy are interpreted according to procedures of the discourse's analysis. The data analysis provide subsides to the implementation of a initial or continuing education program seeking for a posture change in teachers' pedagogic practice.

Key words: Astronomy teaching, Primary School teachers' formation, misconceptions in Astronomy, conceptual mistakes in textbooks, discourse analysis.

\section{INTRODUÇÃO}

No ensino da Astronomia encontram-se diversos problemas que necessitam ser estudados visando a melhoria da qualidade do ensino nesta área, principalmente nas escolas de nível fundamental e médio. Um dos problemas está relacionado ao material bibliográfico acessível aos docentes que, além de serem em número reduzido (Camino, 1995), muitas vezes contém sérios erros conceituais, como é o caso de livros didáticos; exigindo do docente sólidos conhecimentos na área, conforme diagnósticos anteriores (Canalle, 1997 e Trevisan, 1997).

O presente trabalho tem por principais objetivos: a) analisar estudos já realizados sobre as concepções alternativas mais comuns presentes em docentes e alunos sobre temas relacionados à Astronomia; os erros conceituais mais freqüentes em livros didáticos sobre o tema; e sugestões presentes nos Parâmetros Curricu-

lares Nacionais; b) interpretar os discursos de professores de Ciências dos anos iniciais do Ensino Fundamental sobre fenômenos astronômicos necessários à sua prática docente, mapeando suas dificuldades sobre estes; c) a partir dos discursos dos docentes e de resultados de pesquisas contemporâneas sobre a Educação em Ciências, subsidiar o desenho de um programa de educação continuada a docentes nesta área, visando contribuir para uma mudança de postura dos mesmos.

Portanto, as questões que fazem parte de uma problemática geral que esta pesquisa procurou responder foram as seguintes: Quais os padrões relativos às perspectivas dos professores dos anos iniciais do Ensino Fundamental em relação ao ensino 
da Astronomia? Quais são as justificativas para a necessidade do aprimoramento do ensino de Ciências no que tange à Astronomia? Quais são as representações dos professores dos anos iniciais do En- sino Fundamental sobre a inserção deste tema na formação de docentes?

Relatam-se aqui os resultados desse estudo.

\section{Pesquisas sobre as concepções alternativas a Respeito de Astronomia bÁsICA}

A partir de pesquisas já efetuadas sobre concepções espontâneas de estudantes, como por exemplo, em Nardi (1989), Baxter (1989), Barrabín (1995), Camino (1995) e Stahly (1999), pode-se destacar diversas concepções alternativas ou idéias de senso comum, quer sejam em jovens em fase escolar, quer sejam em adultos, provavelmente provenientes do deficiente ensino de Astronomia e "talvez a falha está ligada diretamente à formação do professor" Maluf (2000). De fato, "a carência dos professores e alunos continua muito grande em Astronomia" (Bretones, 1999).

Analisando tais pesquisas, é comum observar nos estudantes as seguintes concepções alternativas em Astronomia: as diferenças entre as estações do ano são causadas devido à distância da Terra em relação ao Sol; as fases da Lua são interpretadas como sendo eclipses lunares semanais; persistência de uma visão geocêntrica do Universo; existência de estrelas entre os planetas do Sistema Solar; desconhecem o movimento aparente das estrelas no céu com o passar das horas, incluindo o movimento circular das mesmas no pólo celeste; associam a presença da Lua exclu- sivamente ao céu noturno, admirando-se do seu aparecimento durante certos dias em plena luz do Sol; associam a existência da força de gravidade com a presença de ar, acreditando que só existe gravidade onde houver ar ou alguma atmosfera (Nardi e Carvalho, 1996).

Outras pesquisas apontam que até mesmo entre docentes verifica-se a persistência de concepções alternativas, semelhantes àquelas diagnosticadas em estudos realizados com estudantes (Teodoro, 2000).

Para Barros (1997), esta situação se dá devido, principalmente, a cinco causas. Primeiro, às dificuldades cognitivas deste tema e de outros relacionados, tais como ótica, luz ou geometria. Segundo, à ausência de evidências claras e perceptíveis que provem o movimento terrestre.

Terceiro, à metodologia de ensino, geralmente caracterizada pelo excesso de leitura e interpretação de textos e, por falta de observações diretas do céu, nem sempre estimuladas pelos livros didáticos. Quarto, à deficiente formação dos professores neste campo da Astronomia, tanto do ponto de vista teórico como prático. Muitos dos professores em exercício ou em formação sustentam conce- 
pções alternativas semelhantes aos de seus alunos, o que apenas multiplica estes erros conceituais. E finalmente, ao tipo de vida cada vez mais urbano, que não facilita as observações do céu noturno, devido à poluição luminosa, ou seja, à luz excessiva que ofusca o brilho dos corpos celestes.

Para Nascimento (1989), muitos conteúdos sobre Astronomia são altamente divulgados pela imprensa e trazem a vantagem de despertar curiosidade e admiração entre os alunos. Por outro lado, "é provável que grande parte das informações veiculadas pelos professores e as concepções prévias dos alunos tenha origem na mídia" (Bretones, 1999). Ademais, filmes de ficção científica são responsáveis por aguçar a curiosidade (Fraknoi, 1995); muitos destes filmes, que abordam situações em órbita da Terra, onde astronautas flutuam num ambiente de baixa gravidade, conquistas de outros planetas, com suas atmosferas inóspitas, viagens intergalácticas com seres extraterrestres (embora neste caso também nem sempre representem a realidade, como o som de explosões espaciais em pleno vácuo, por exemplo), provocam dúvidas e despertam sua curiosidade e atenção.

\section{Os PARÂMETROS CURRICULARES NACIONAIS E O ENSINO DA ASTRONOMIA}

Quais são as abordagens para o ensino de Astronomia previstos nos PCN (Parâmetros Curriculares Nacionais)? Uma primeira análise dos PCN para o Ensino Médio leva a crer que a Astronomia merece um tratamento mais aprofundado do que costumeiramente ocorre nas instituições de ensino, necessitando a inserção de mais conteúdos deste tema nas mais variadas disciplinas (Bretones, 1999). Ainda, a Astronomia é de fato uma disciplina inteiramente interdisciplinar, pois conforme os referidos $\mathrm{PCN}$, os assuntos relacionados com Astronomia são tratados em outras disciplinas tais como Biologia, Física e Química, no contexto interdisciplinar que preside o ensino de cada disciplina e do seu conjunto. Ao relacionar a hipótese da formação da Terra com outros campos do conhecimento como Geologia, Física e Astronomia, o aluno pode entender que existe um universo muito abrangente de explicações sobre a Terra primitiva (Brasil, 1999).

Os PCN do Ensino Fundamental encorajam o aproveitamento, da parte do professor em seu planejamento de ensino, da grande variedade de conteúdos teóricos das disciplinas científicas, dentre elas, a Astronomia, com todo o seu acúmulo de conhecimentos tecnológicos. Porém, ao contrário da tecnologia, que é produzida com uma finalidade prática, o conhecimento das ciências naturais (que inclui Astronomia), 
visam a "compreensão sobre o Universo, o espaço, o tempo, a matéria, o ser humano, a vida, seus processos e transformações" (Brasil, 1999).

De acordo com os PCN, o eixo temático "Terra e Universo" está presente somente a partir do terceiro ciclo por motivos circunstanciais, mas entende-se que "este eixo poderia estar presente nos dois primeiros" (Brasil, 1998). Porém, os PCN advogam que a Astronomia deve fazer parte do conteúdo dos anos iniciais do Ensino Fundamental, quando mencionam que "a grande variedade de conteúdos teóricos das disciplinas científicas, como a Astronomia, a Biologia, a Física, as Geociências e a Química, assim como dos conhecimentos tecnológicos, deve ser considerada pelo professor em seu planejamento" (Brasil, 1997).
Visando um aprendizado prático do conteúdo em Astronomia, os PCN ainda salientam a necessidade de "atividades práticas, e visitas preparadas a observatórios, planetários, associações de astrônomos amadores, museus de Astronomia e de Astronáutica" (Brasil, 1999). De um modo geral, admite-se que o professor de Ciências do ensino fundamental deva estar preparado para fornecer subsídios aos alunos a fim de que eles sejam capazes de principalmente: identificar algumas constelações mediante observação direta, compreender a atuação da atração gravitacional, o mecanismo de funcionamento do dia, da noite e das estações do ano, as distinções entre as teorias geocêntrica e heliocêntrica, estabelecendo relações espaciais e temporais na dinâmica e composição da Terra, e finalmente valorizar o conhecimento historicamente acumulado em Astronomia.

\section{ERROS CONCEITUAIS MAIS FREQÜENTES DE ASTRONOMIA}

\section{EM LIVROS DIDÁTICOS}

Em muitos casos, devido à região onde se encontra no país, o professor de Ciências possui como "única fonte de consulta" o próprio livro didático (Maluf, 2000). Por isso, caso se encontre alguma falha conceitual em qualquer um deles, este necessita de uma correção adequada.

Como está a situação do livro didático brasileiro em relação à Astronomia? Antes, o que o classificaria como sendo um bom instrumento de ensino para Ciências? Entende-se por um ‘bom' livro didático de Ciências aque- le que leva em consideração, no mínimo os cinco pontos fundamentais descritos a seguir, segundo especifica Bizzo (1996): primeiro, o livro não deveria se limitar simplesmente ao incentivo à memorização de enunciados, fórmulas ou termos técnicos. Segundo, as atividades propostas pelos livros didáticos devem incluir demonstrações eficazes e atividades experimentais bem formuladas. Conforme Trevisan (1997), os exercícios devem promover a boa leitura, a oralidade, a escrita, a reflexão, a pesquisa e a criatividade. Terceiro, 
o aluno deveria, ao usar o livro, perceber a interdisciplinaridade constante em seu conteúdo. Quarto, a cultura, a experiência de vida e os valores éticos e religiosos dos alunos devem ser respeitados. Quinto, as figuras e ilustrações devem ter a precaução de transmitir a veracidade das informações, tanto mais atualmente quando os livros de ciência mais modernos se caracterizam por uma crescente utilização de imagens e recursos gráficos (Martins, 1997). Além, segundo Trevisan (1997), para se tornar aceitável, o livro didático de Ciências precisa libertar o estudante dos "preconceitos, do misticismo, da magia e das crendices presentes no seu cotidiano", o que se aplica diretamente à Astronomia.

Para Fracalanza (1992), "a partir dos resultados das diversas pesquisas que analisam os livros didáticos de Ciências no Brasil, o panorama que se descortina não é nada alentador". A pesquisa sobre erros conceituais em livros didáticos de Ciências, incluindo o tema Astronomia, já vem sendo realizada por muitos especialistas na área, trazendo uma contribuição para a educação brasileira, dentre os quais citam-se: Bizzo (2000), Trevisan (1997), Nardi (1996), Canalle (1994 e 1997) e Paula e Oliveira (2002). Dentre outros erros conceituais encontrados nestes livros, pode-se destacar para o momento, sem entrar em muitos detalhes, os seguintes conteúdos com os erros mais comuns de Astronomia: estações do ano, Lua e suas fases, movimentos e inclinação da Terra, representação de constelações, estrelas, dimensões dos as- tros no Sistema Solar, número de satélites e anéis em alguns planetas, cometas, pontos cardeais e características planetárias.

Há ainda de se acrescentar que os livros didáticos falham no aspecto do incentivo à observação prática, deixando de induzir o aluno a analisar os fenômenos do céu, no seu dia a dia, estimulando a pesquisa e a observação, provando que no processo de ensino e aprendizagem de Astronomia deve-se incluir principalmente a prática observacional. Quando possuem alguma indicação para realização de um experimento prático, geralmente faltam informações nas suas instruções, impossibilitando o aluno e o professor de realizá-lo (Canalle, 1997). Muitas ilustrações e desenhos também deixam a desejar no aspecto de detalhes confiáveis, trazendo à tona mais erros conceituais sobre fenômenos astronômicos, conforme Paula e Oliveira (2002) e Bizzo (1996).

Além disso, informações adicionais sobre o assunto, ou onde procurar mais detalhes a respeito, para sanar as curiosidades naturais dos alunos, deixam a desejar nestes livros. A quantidade de conteúdo também se torna mínima quando comparada com outros conteúdos dentro do próprio livro, sendo dedicadas poucas páginas para a Astronomia (Trevisan, 1997).

A avaliação dos livros didáticos realizada pelo MEC possibilitou a incorporação destas críticas e correções em diversas publicações. Entretanto, há ainda exemplares com erros conceituais, ou no mínimo, com 
afirmações incompletas que sugerem interpretações alternativas. Numa pesquisa realizada por Leite e Hosoume (1999), por exemplo, constatou-se que alguns dos livros didáticos mais vendidos na cidade de São Paulo, mesmo após a avaliação do MEC, apresentavam afirmações vagas, como 'o Sol é uma estrela de quinta grandeza', e lacunas de informações, como sendo Saturno o único planeta a possuir anéis. Alguns outros erros conceituais persistiram nestes livros analisados, tal como o conceito das estações do ano, com a idéia de que o verão e o inverno dependem da distância Terra-Sol. Assim, Leite e Hosoume (1999) demonstram, dentre as suas conclusões parciais, a crítica de que o livro didático continua a apresentar os conteúdos de Astronomia de maneira fragmentada, pouco profunda e não suficiente para a explicação das muitas questões veiculadas através dos meios de comunicação que causam curiosidades em alunos e professores.

\section{Por que ensinar Astronomia?}

Quais são as justificativas para se ensinar Astronomia? Dentre muitas, pode-se destacar algumas. Ao aprender sobre o espaço sideral, o estudante desenvolve habilidades que são fundamentais para o aprendizado de outras disciplinas (Barros, 1997). Algumas destas habilidades são: melhoria na capacidade de cálculos matemáticos, comparação e classificação de objetos ou eventos, comunicação, experimentação, exploração, imaginação, medição, observação, organização, raciocínio lógico, aplicação, avaliação, dedução, descrição, interpretação, predição, manipulação de instrumentos e reconhecimento de pré-conceitos (Fraknoi, 1995).

Outra justificativa para o ensino de Astronomia deve-se ao fato de que muitos estudantes possuem conceitos espontâneos sobre o Universo que nos rodeia, conforme especificado nas citações anteriores. Para citar apenas alguns exemplos, quantas crianças conseguem realmente entender que o nosso planeta possui um formato esferoidal, ou como se formam as fases da Lua, ou as estações do ano? Cabe ao educador fornecer a ajuda necessária para que os estudantes venham a mudar suas concepções (Ponser et al, 1982), ou alterar o seu perfil conceitual (Mortimer, 1995), desde que eles também estejam dotados do interesse de aprender (Osborne e Wittrock, 1985).

Além disso, o conjunto destes inúmeros erros conceituais em livros didáticos é um dos fatores que contribuem para um conhecimento repleto de concepções espontâneas que não correspondem à realidade científica, o que produz teorias particulares a respeito de fenômenos astronômicos e corpos celestes, podendo ser tratadas como idéias prévias pelo profissional de ensino, 
o qual, utilizando-se de recursos apropriados, tentará levar o aluno à mudança conceitual (Camino, 1995).

Para Beatty (2000), os educadores estão percebendo que ao oferecer a Astronomia no Ensino Médio e Superior, o retorno tem sido alto. Muitos alunos e professores ficam dotados de mais incentivo científico ao observar as imagens reais do Universo através de um telescópio, algo que muitos nunca haviam visto antes. Isto pode motivar o estudante e o próprio educador, levando-os a se envolver mais com outras questões fundamentais do uma vez que "os fenômenos astronômicos fornecem um farto material de observações que podem ser trabalhados e conduzidos a um modelo científico do fenômeno" (Nascimento, 1989).

Conforme Nussbaum (1990), o ensino de Astronomia possui um grande potencial educativo. Concretiza-se este fato tanto mais quando se considera que a Astronomia é capaz de interagir facilmente com praticamente todas as disciplinas, fazendo dela "uma matéria claramente interdisciplinar" (Barros, 1997). Sendo a mais antiga das ciências, ela foi utilizada pelos povos mais primitivos, embora que de uma maneira mística, pendendo mais para o lado da Astrologia do que propriamente Astronomia. De qualquer forma, o estudo do céu sempre se fez presente no decorrer de toda a história da humanidade, acompanhando o surgimento das outras ciências e testemunhando todos os fatos históricos mais relevantes. Foram os egípcios, babilônicos e chineses os primeiros povos a realizarem obser- vações sistemáticas dos corpos celestes (Mourão, 1998).

A Astronomia está presente nas chamadas Ciências Naturais, nas Ciências Sociais, nas Artes, na Música e na Literatura (Fraknoi, 1995). $\mathrm{Na}$ estrutura curricular das escolas de Ensino Fundamental e Médio a Astronomia pode estar presente na Língua Portuguesa, na Química, Física, Biologia, Matemática, Poesia, Psicologia, Meio Ambiente, Arqueologia, Geologia, Mídia, Sociologia.

É importante que o professor conheça com mais profundidade a Astronomia e, conseqüentemente a História da Ciência para que tenha competência em propor atividades integradas, interdisciplinares, como as levantadas acima, aos docentes responsáveis pelas demais disciplinas presentes no currículo para que as relações acima sejam asseguradas. Isso pode ocorrer quando o projeto pedagógico da escola é construído coletivamente, envolvendo todos os atores que irão desenvolvê-lo.

Os estudantes devem ser conscientizados de sua responsabilidade enquanto seres humanos habitantes do planeta. Assim, uma das justificativas para o ensino de Astronomia é que esta pode levar os alunos a compreender a imensidão do Universo e a necessidade da população participar nos destinos do planeta, ampliando a dimensão apenas acadêmica do ensino e levando os estudantes à construção da cidadania.

Atualmente, telescópios sofisticados e naves espaciais perscrutam o espaço numa busca de respostas 
que desvendem os enigmas do Universo, trazendo uma das mais importantes contribuições desta antiga ciência: a conscientização das pessoas quanto à importância da preservação do planeta Terra e do meio ambiente como sustentação da vida. A divulgação destas atividades desperta a criança para o aprendizado, favorecendo sua curiosidade natural. Segundo Rutherford e Ahlgren (1990), "a educação científica que estimula a curiosidade e ensina as crianças a canalizarem essa curiosidade de maneiras produtivas serve tanto os estudantes como a própria sociedade".

Como última justificativa para a importância do ensino da Astronomia, pode-se citar a sua característica de facilitadora na mudança de concepções. Embora muitas vezes o conteúdo a ser ensinado não seja familiar ao estudante, o docente dever estar consciente que estes já possuem sua estrutura cognitiva individual, ou "paradigma dominante" (Kuhn, 1987), ou ainda segundo Posner et al (1982), uma "ecologia conceitual". Isso nem sempre é levado em conta pelo docente. Conforme Villani (1984), ao preparar sua aula, o docente considera que os alunos sabem bem pouco sobre 0 assunto ensinado, ou então, que possuem conhecimento distorcido a respeito do assunto. Outros desconsideram completamente o conhecimento que o aluno traz para a sala de aula, ou pior ainda, "parte-se do pressuposto de que o aluno apresenta completo vazio intelectual, a ser preenchido na escola" (BIZZO, 1996). Em contraste com este pensamento,
Driver (1989) indica "que as crianças vêm para as aulas de Ciências com concepções prévias que podem diferir substancialmente das idéias a serem ensinadas, que estas concepções influenciam a aprendizagem futura e que elas podem ser resistentes a mudanças".

Tentando levar para a prática docente os resultados dessas pesquisas construtivistas recentes, uma das propostas para o ensino de Astronomia (Sneider, 1995) sugere que os estudantes descubram as idéias de Astronomia por elas mesmas, utilizando-se principalmente de atividades práticas e simples, mas sempre levando em consideração suas próprias idéias e pensamentos a respeito do assunto que está sendo estudado. Isto está em conformidade com a proposta de ensino por pesquisa em Gil Pérez (1999). Ainda como facilitador da mudança de seus paradigmas, ou concepções, "o processo de aprendizado de uma teoria depende do estudo das aplicações, incluindo-se aí a prática na resolução de problemas" (Kuhn, 1987).

Em conformidade com os PCN, a proposta de atividades práticas de Astronomia para os alunos, tais como construir instrumentos simples semelhantes aos primitivos relógios de Sol, gnômons (Ten, 1984), realizar observações do Sol, da Lua, das estrelas e dos meteoros, marcando suas observações e dados, fará com que estes consigam identificar padrões em seus dados anotados, aprender a utilizar equipamentos científicos para comprovar suas informações, e sejam capazes de cons- 
truir modelos para explicar os fenômenos que eles mesmos descobriram.

Tanto alunos como professores podem apresentar concepções alternativas sobre o tema, muitas vezes originadas de distorções no ensino escolar, como por exemplo, aquelas referentes à curvatura da Terra, às fases da Lua e as justificativas para a causa das estações do ano, comumente presentes na literatura, conforme já citado. Estas concepções alternativas acabam se tornando suas próprias teorias particulares ou paradigmas (Kuhn, 1987). Desta forma, para se entender a maioria dos fenômenos científicos e naturais, as pessoas elaboram consciente ou inconscientemente, suas teorias particulares, ou idéias próprias que tentam explicar determinado fenômeno ou acontecimento científico, formando uma estrutura cognitiva (Posner et al, 1982). De qualquer modo, é apropriado tratar estas teorias particulares ou idéias prévias (Camino, 1995) dos estudantes em vez de tentar substituí-las de uma vez pelo conhecimento científico, tendo como finalidade uma mu- dança nos conceitos (Posner et al, 1982) ou no perfil conceitual (Mortimer, 1995).

Segundo Villani (1984), as informações que nos são lançadas podem assumir quatro resultados possíveis: podem passar por nossa mente sem deixar vestígios, podem nos causar uma leve impressão momentânea, podem permanecer gravadas na mente de um modo apenas periférico, ou podem modificar profundamente nossa maneira de pensar. Portanto, o papel do professor que ensina Ciências e, sobretudo Astronomia, precisa ter em mente qual destes tipos de resultados vai querer obter ao ensinar.

Cabe aos professores a tarefa de orientar os estudantes, sugerindo atividades práticas que sejam não só educacionais, mas que despertem o interesse pela Ciência (Costa e Gomez, 1989). Este papel o docente só pode desempenhar com segurança quando convive em sua formação com um processo desta natureza.

\section{Métodos da pesquisa e forma DE ANÁLISE DOS RESULTADOS}

A pesquisa aqui relatada pode ser classificada como de natureza qualitativa, pois conforme Bogdan e Biklen (1991), uma pesquisa deste tipo possui cinco características: a fonte direta de dados é o ambiente natural, constituindo o investigador o instrumento principal; a investi- gação qualitativa é descritiva; os pesquisadores qualitativos interessam-se mais pelo processo do que simplesmente pelos resultados; eles tendem a analisar os seus dados de forma indutiva; o significado é de importância vital na abordagem qualitativa. 
A partir dos dados obtidos pela fundamentação teórica, o instrumento escolhido para o levantamento de dados em campo foi o das entrevistas clínicas, semi-estruturadas, que proporcionaram a interpretação dos discursos dos docentes sobre tópicos ligados à Astronomia e sobre suas práticas de ensino, bem como suas dificuldades em relação ao ensino deste tema. Todas as entrevistas foram filmadas e gravadas em fitas de videocassete.

De acordo com Bogdan e Biklen (1991), a entrevista é uma conversa intencional, dirigida por uma pessoa com o objetivo de obter informações sobre outra. Na investigação qualitativa, as entrevistas podem ser a estratégia dominante para conseguir dados ou apenas fazer parte de um conjunto maior de outras fontes de dados. Começam com uma conversa informal e depois vão se especificando as perguntas, até se tocar no assunto em questão espontaneamente pelo entrevistado, ou não.

Seguindo o procedimento sugerido pelos autores citados acima, este levantamento foi realizado inicialmente numa amostra de dez docentes -cujas entrevistas foram registradas em vídeo- todos dos anos iniciais do Ensino Fundamental em atividades de educação continuada na região da Nova Alta Paulista, no Estado de São Paulo. A investigação foi baseada em pesquisas já realizadas sobre o ensino de temas de Astronomia e matérias afins, conforme Nardi (1994), Nardi e Carvalho (1996), Baxter (1989) e Barrabín (1995), por exemplo.
A partir dos dados recolhidos com essa amostra constituída de dez profissionais, todas do sexo feminino, escolheu-se cinco das entrevistas para proceder à análise do discurso, uma vez que após a visualização da filmagem por diversas vezes, constatou-se uma certa recorrência de informações na amostra inicial, uma vez que as formações dos sujeitos eram semelhantes. Portanto, foram analisadas cinco das entrevistas, cujos sujeitos possuem experiência profissional no magistério que variam desde 5 até 25 anos, provenientes dos anos iniciais do Ensino Fundamental (1 $1^{\mathrm{a}}$. a $4^{\mathrm{a}}$. séries). Todas as entrevistas foram realizadas e filmadas em uma sala de aulas, onde somente o pesquisador e o entrevistado estiveram presentes.

Para a análise dos dados das entrevistas, utilizou-se princípios e procedimentos da análise do discurso em sua linha francesa, a partir de estudos de D. Maingueneau (1997) e E. Orlandi (2000). Segundo esses autores, o suporte do discurso ou o meio pelo qual se concentram ou se materializam vários discursos se dá pelo indivíduo, do grupo ao qual representa. A análise do discurso, dessa forma, possibilita ao investigador descobrir os meandros do pensamento expresso por um determinado indivíduo ou grupo social. Conforme Maingueneau (1997), uma das tarefas mais importantes da análise do discurso é classificar os discursos que são produzidos numa sociedade. Embora o que caracteriza um discurso não é o seu tipo, mas o seu modo de funcionamento, Orlandi (2002) apresenta exemplos de 
tipologias de discursos que se reflete nas diferentes instituições e suas normas: discurso político, jurídico, religioso, jornalístico, etc. Voltandose para a importância dos modos de funcionamento, apresentam-se critérios para se distinguir suas diferenças, totalizando pelo menos três discursos: autoritário (polissemia é contida), polêmico (está entre polissemia e paráfrase) e lúdico (polissemia aberta).

Um enunciado não o é por si só. $A$ matéria lingüística é apenas uma parte dele, pois existe uma outra parte que não é verbal: o contexto da enunciação (Brandao, 2002). Considerando que a linguagem é interação e um modo de produção social, ela não é neutra, pois possui uma intencionalidade. Ela também não é natural nem inocente. Por isso, a linguagem, enquanto discurso, está carregada de ideologia. O texto é assim o lugar, o centro comum que se faz no processo de interação entre falante e ouvinte, autor e leitor (Orlandi, 1996). Há uma relação entre o já-dito e o que se está dizendo, ou seja, entre o interdiscurso e o intradiscurso, ou ainda, entre a constituição do sentido e sua formulação (Orlandi, 2002). O interdiscurso é o conjunto de formulações realizadas e já esquecidas que determinam o que se diz.

A análise do discurso visa compreender como os objetos simbólicos produzem sentidos. Não há verdade oculta atrás do texto, mas há gestos de interpretação. Daí a inteligibilidade, interpretação e a compreensão (Orlandi, 2002). Portanto, em outras palavras, a análise do discurso visa a compreensão na mesma medida em que visa explicitar a história dos processos de significação, para atingir os mecanismos de sua produção, o que permeia o procedimento de análise das entrevistas dos professores dos anos iniciais do Ensino Fundamental com respeito ao ensino da Astronomia presente nesta pesquisa.

\section{Alguns dados coletados E CONSIDERAÇÕES FINAIS}

Com a análise dos discursos dos docentes da amostra foi possível verificar que, embora reconhecem suas dificuldades com o ensino da Astronomia, a maioria delas expressou o seu gosto pelo tema, e lamentaram suas limitadas capacidades para ensiná-lo, uma vez que não trabalharam com conteúdos de Astronomia em sua formação inicial. Também demonstraram a aceitação e o interesse dos seus alunos em aprender este tema, uma vez que muitos de seus conteúdos despertam sua curiosidade, principalmente devido à notícias da mídia, embora não se deva considerá-las como fonte fidedigna de conteúdos escolares.

Os dados obtidos juntamente com o levantamento teórico apontam para um possível padrão de atitudes para com o ensino da Astronomia, que podem ter início desde momentos 
bem anteriores à formação do professor. Mesmo antes de iniciar sua formação, algumas concepções alternativas sobre fenômenos astronômicos estão firmemente arraigadas no futuro docente, que podem ter tido sua origem nas mais diversas fontes, incluindo a própria educação que recebeu enquanto criança, nos seus anos iniciais do Ensino Fundamental. Atingindo a formação, essas concepções normalmente persistem, em parte resultado de um curso de graduação falho ou isento de conteúdos em ensino de Astronomia. Daí a importância da inserção da Astronomia na formação desses docentes.

Esta inserção é apoiada pela importância atribuída à presença de conteúdos nos cursos de formação de professores, pois conforme as Diretrizes Curriculares Nacionais para a Formação de Professores da Educação Básica (Brasil, 2004), para desenvolver o seu trabalho, o professor precisa compreender os conteúdos das áreas do conhecimento que serão objeto de sua atuação didática, o que inclui temas de Astronomia. Mas para que esta compreensão seja possível, os conteúdos devem estar presentes na formação do professor, de modo a ir além daquilo que será trabalhado em sua prática docente com as crianças e os jovens, uma vez que o conteúdo assume um papel central no desenvolvimento de competências.

Seguindo as sugestões metodológicas fornecidas pela amostra de professores, a inserção da Astronomia na formação do docente se daria por meio dos seguintes ítens: elaboração de cursos e palestras, material didá- tico com linguagem acessível (livro, projeto, pôster, filme, slide), preparação de atividades práticas para alunos (maquetes, aulas externas), aumento de conteúdos em Astronomia no curso de formação do professor com o aprofundamento adequado, aproveitamento de notícias recentes da mídia e de fenômenos astronômicos, criação de um site na internet para o auxílio do professor ou um boletim comum tal como um jornal informativo, visitas ao planetário e observatório, contextualização da Astronomia, e a correção de concepções alternativas criadas pelos erros conceituais em livros didáticos.

Além disso, a interpretação dos discursos dos professores da amostra conjugada com o levantamento bibliográfico das pesquisas em Educação em Ciências na área da Astronomia, permitiu o surgimento de orientações didáticas sob a forma de tópicos astronômicos e atividades práticas, tais como a observação celeste a olho nú, identificação dos corpos celestes (planetas, estrelas, constelações), orientação e sistemas de medidas no espaço e no tempo através da Astronomia, funcionamento de instrumentos astronômicos, Sistema Solar (características dos planetas, asteróides, cometas, satélites naturais, anéis, distâncias, dimensões, órbitas), objetos do céu profundo (nebulosas, aglomerados, galáxias), fenômenos astronômicos (dia/noite, estações do ano, meteoros, eclipses, fases da Lua), e tecnologia espacial brasileira.

Manifestas, portanto, as dificuldades relatadas nos discursos das professoras da amostra, bem como suas 
sugestões para o emprego de um ensino de qualidade em Astronomia nos anos iniciais do Ensino Fundamental, e entrelaçando os dados assim obtidos com a fundamentação teórica e as referidas diretrizes, prevê-se a instalação de um progra- ma de educação continuada para professores deste nível, e a inserção deste tema na formação inicial desses docentes para que compreendam e identifiquem as principais áreas para mudanças em sua prática pedagógica em relação ao ensino da Astronomia.

\section{RefERÊNCIAS}

Barrabín, J. M. (1995) ¿Por qué hay veranos e inviernos? Representaciones de estudiantes (12-18) y de futuros maestros sobre algunos aspectos del modelo Sol-Tierra. Enseñanza de las Ciencias, 13(2), 227-236.

Barros S. G. (1997) La Astronomía en textos escolares de educación primaria. Enseñanza de las Ciencias, 15 (2), 225-232.

Baxter, J. (1989) Childrens' understanding of familiar astronomical events. International Journal of Science Education, 11, special issue, pp. 502-513.

Beatty, K. (sept/2000) Where are the Young astronomers? Sky \& Telescope. Estados Unidos da América. Skypub. 100 (3), 82-86.

Bizzo, N. et al. (jun.,1996) Graves erros de conceito em livros didáticos de ciência. Ciência Hoje, 121 (21):26-35, .

Bizzo, N. (abril, 2000) Falhas no ensino de ciências. Ciência Hoje, 159 (27), 26-31.

Bogdan, R. C. e Biklen, S. K. (1991) Investigação qualitativa em educação. Portugal: Porto Editora.

Brandãho, H. H. N. (2002) Introdução à análise do discurso. $8^{\circ}$ ed. São Paulo: Editora da UNICAMP.

Bretones, P. S. (1999) Disciplinas introdutórias de Astronomia nos cursos superiores do Brasil. Dissertação de Mestrado, Instituto de Geociências, UNICAMP.

Camino, N. (1995) Ideas previas y cambio conceptual en Astronomía. Un estudio con maestros de primaria sobre el día y la noche, las estaciones y las fases de la luna. Enseñanza de las Ciencias, 13 (1), 81-96.

Canalle, J. B. G. e Oliveira, (1994) I.A.G. Comparação entre os tamanhos dos planetas e do Sol. Caderno Catarinense de Ensino de Física, 11 (2), 141-144.

Canalle, J. B. G. et al. (1997) Análise do conteúdo de Astronomia de livros de geografia de $1^{\circ}$ grau. Caderno Catarinense de Ensino de Física, 14 (3), 254-263.

Costa, A. A. e Gomez, V. R. (1989) La Astronomía en la enseñanza obligatoria. Enseñanza de las Ciencias, 7 (2), 201-205.

Driver, R. (1989) Students' conceptions and the learning of science. International Journal of Science Education, 11, special issue, pp. 481-490.

Fracalanza, H. (1992) O que sabemos sobre os livros didáticos para o ensino de ciências no Brasil. Tese de Doutorado, Faculdade de Educação, UNICAMP.

Fraknoi, A. An Introduction. In: ed. The universe at your fingertips: an astronomy activity and resource notebook. Estados Unidos da América. Project Astro. 1995. Cap. 1, p. 1-4.

Gil Perez, D. et al. (1999) ¿Puede hablarse de consenso constructivista en la educación científica? Enseñanza de las Ciencias, 17 (3), 503-512.

Khun, T. S. (1987) As estruturas das revoluções cientificas. São Paulo. Perspectiva. 
Leite, C. e Hosoume, Y. (1999) Astronomia nos livros didáticos de ciências da $1^{\text {a }}$. à $4^{\text {a }}$. séries do ensino fundamental. Em: SIMPÓSIO NACIONAL DE ENSINO DE FÍSICA, 13, São Paulo, 1999. Caderno de resumos e programação, São Paulo: SBF.

Maingueneau, D. (1997) Os termos-chave da análise do discurso. Lisboa: Gradiva.

Maingueneau, D. (1997) Novas tendências em análise do discurso. Campinas: Pontes.

Maluf, V. J. (2000) A Terra no espaço: a desconstrução do objeto real na construção do objeto cientifico. Dissertação de Mestrado. Instituto de Educação, Universidade Federal de Mato Grosso.

Martins, I. (novembro, 1997) O papel das representações visuais no ensino-aprendizagem de ciências. Atas do I Encontro Nacional de Pesquisa em Ensino de Ciências. Águas de Lindóia, SP, pp. 27-29.

Ministério da Educação de Brasil (2001). Conselho Nacional de Educação. Diretrizes Curriculares Nacionais para a Formação de Professores da Educação Básica, em nível superior, curso de licenciatura de graduação plena. Parecer CNE/CP No. 9/2001, pub no DOU de 18/01/2002. Brasília: MEC. Disponível em <http://www.mec.gov.br>. Acesso em: março, 2004.

Mortimer, E. F. (1995) Construtivismo, mudança conceitual e ensino de ciências: para onde vamos? Em: Escola de Verão para professores de prática de ensino de Física, Química e Biologia, 3, 1994, Serra Negra. Coletânea. São Paulo: FEUSP, pp. 56-74.

Mourão, R. R. F. (1998) Da Terra às galáxias -uma introdução à astrofísica. Vozes, Rio de Janeiro: Vozes.

Nardi, R. (1989) Um estudo psicogenético das idéias que evoluem para a noção de campo-subsídios para a construção do ensino desse conceito. Tese de doutorado. Faculdade de Educação, Universidade de São Paulo.
Nardi, R. (1994) História da ciência x aprendizagem: algumas semelhanças detectadas a partir de um estudo psicogenético sobre as idéias que evoluem para a noção de campo de força. Enseñanza de las Ciencias, 12 (1), 101-106.

Nardi, R. e Carvalho, A. M. P. (1996) Um estudo sobre a evolução das noções de estudantes sobre espaço, forma e força gravitacional do planeta Terra. Investigações em ensino de ciências, 1 (2), Porto Alegre. UFRGS.

Nardi, R. (1996) Avaliação de livros e materiais didáticos para o ensino de ciências $e$ as necessidades formativas do docente. Em: BICUDO, M. A.V. e SILVA Jr., C.A. Formação do Educador e avaliação institucional. v. 1, São Paulo: Editora Unesp, pp. 93-103.

Nascimento, S. S. (1989) Um curso de gravitação para professores de primeiro grau. Dissertação de Mestrado. Faculdade de Educação, Universidade de São Paulo.

Nussbaum, J. (1995) Astronomy teaching: challenges and problems, IVth International Conference on Teaching Astronomy, Barcelona (1990). Investigación didáctica en Astronomía: una selección bibliográfica. Enseñanza de las Ciencias, 13 (3), 387-389.

Orlandi, E. P. (1996) A linguagem e seu funcionamento-as formas do discurso. $4^{\circ}$ ed. São Paulo: Pontes.

Orlandi, E. P. (2000) Discurso e leitura. $8^{\circ}$ ed. São Paulo: Cortez.

Orlandi, E. P. (2002) Análise de discursoprincípios e procedimentos. $4^{\circ}$ ed. São Paulo: Pontes.

Osborne, R. e Wittrock, M. (1985) The generative learning model and its implications for science education. Studies in Science Education, 12, pp. 59-87.

Paula, A.S.P. e Oliveira, H.J.Q. Análises e propostas para o ensino de Astronomia. 
[on line] Disponível na internet via WWW. URL: http://cdcc-gwy.cdcc.sc.usp.br/cda/ erros-no-brasil/index.html. Arquivo capturado em 15 de janeiro de 2002.

Posner, G. J. et al. (1982) Accomodation of a scientific conception: toward a theory of conceptual change. Science Education, 66, pp. 211-27.

Rutherford, F. J. e Ahlgren, A. Ciência para todos. Gradiva: Lisboa, 1990.

Secretaria de Educação Média e Tecnologia de Brasil (1999) . Parâmetros Curriculares Nacionais: Ciências da natureza, matemática e suas tecnologias. Brasília. MEC/ SEMTEC.

Secretaria de Educação Média e Tecnologia de Brasil (1998). Parâmetros Curriculares Nacionais: terceiro e quarto ciclos do ensino fundamental - ciências naturais. Brasília: MEC/SEMTEC.

Secretaria de Educação Média e Tecnologia de Brasil (1997). Parâmetros Curriculares Nacionais: ciências naturais. Brasília: MEC/SEMTEC.

Sneider, C. Learning Astronomy. Em: Fraknoi, Andrew (ed). The universe at your fingertips: an astronomy activity and resource notebook. Estados Unidos da América. Project Astro. 1995. Cap. 3, pp. 713.

Stahly, L. L. et al. (1999)Third grade students' ideas about the lunar phases. Journal of Research in Science Teaching, 36 (2), 159-177.

Ten, A. E. e Monros, M. A. (1984) Historia y enseñanza de la astronomía. Los primitivos instru-mentos y su utilización pedagógica. Enseñanza de las Ciencias, 2 (1), 49-56.

Teodoro, S. R. (2000) A história da ciência $e$ as concepções alternativas de estudantes como subsídios para o planejamento de um curso sobre atração gravitacional. Dissertação de Mestrado, Faculdade de Ciências, UNESP.

Trevisan, R. H. (1997) Assessoria na avaliação do conteúdo de Astronomia dos livros de ciências do primeiro grau. Caderno Catarinense de Ensino de Física, 14 (1), 7-16.

Villani, A. (dez./1984) Reflexões sobre o ensino de Física no Brasil: Práticas, Conteúdos e Pressupostos. Revista de Ensino de Física, 6 (2), 76-95. 